\title{
Interação didática: apontamentos (inter) culturais sobre o uso da palavra e a formação do sujeito aluno
}

\author{
Fernanda de Castro Modl ${ }^{*}$
}

\begin{abstract}
Resumo
O objetivo deste trabalho é discutir sobre a interação didática como um dos contextos dialógicos e discursivos genuínos para a formação do sujeito em termos do uso da palavra em sociedade. Assumindo um olhar dialógico (VOLOCHÍNOV, 1999) - interacional (MEAD, 1962) e metodologicamente amparado em princípios da etnografia, são trazidas cenas de interação didática de dois grupos (um alemão e um brasileiro) de uma mesma etapa de escolarização, a fim de demonstrar que o uso da palavra em sala de aula, ou seja, o modo como professor e alunos se posicionam como falantes e ouvintes em seus dia a dia interacionais, está submetido a convenções culturais, tanto em termos de uma cultura escolar ocidental, quanto de uma cultura escolar local.
\end{abstract}

Palavras-chave: Interação didática. Sala de aula. Formação do sujeito. Cultura escolar. Palavra na sala de aula.

Como professora de Didática da Linguagem desde 2011, tenho centrado meu interesse em estudar a sala de aula como lugar de convivência intersubjetiva e de uso da palavra, isso porque acredito ser fundamental contribuir para que meus alunos, professores de língua materna e estrangeira (inglês) em formação, compreendam a sala de aula, lugar genuíno de sua futura atuação, como um contexto interacional e institucional de formação de sujeitos de linguagem.

Zandwais (2012, p. 14) pondera que "toda atividade de ensino pressupõe pesquisa, e que, nesse sentido, tanto podemos didatizar saberes advindos da pesquisa como fazer pesquisa a partir das necessidades de didatização, e de modo integrado ou não"; isso explica que meu interesse pela sala de aula como um espaço de convivência intersubjetiva, hoje pauta na minha agenda de trabalho na formação inicial de professores, é, portanto, alimentado tanto por pesquisas anteriores sobre interculturalidade e sala de aula (COELHO, 2011), como por trabalhos mais recentes sobre sala de aula e intraculturalidade (MODL; RIBEIRO, 2015a, 2015b).

Universidade Estadual do Sudoeste da Bahia (UESB). 
Nessa direção, este artigo responde ao interesse de demonstrar que cenas de aulas de dois países informam-nos sobre a cultura escolar de modo a contribuir para a diminuição da invisibilidade estrutural e estruturante do que ocorre nas salas de aula nacionais em torno do funcionamento da palavra.

$\mathrm{O}$ enquadre para o funcionamento da palavra em sala de aula foi iniciado em meu doutoramento, quando comecei a olhar para o intercâmbio da palavra em sala de aula para estudar os padrões de comportamento discursivos de alunos e professores de um grupo de alemães e de brasileiros. ${ }^{1}$ A partir daí, ficou evidenciado que o uso da palavra em sala de aula revela traços culturais do modo como sociedades representam a própria instituição escola e projetam os papéis comunicativos e sociais de aluno e professor, o que, certamente, alimenta a compreensão da sala de aula como um espaço discursivo de formação do sujeito.

À luz dessa perspectiva, venho defendendo a necessidade de se considerar, nas disciplinas da área de metodologia e práticas de ensino na formação do professor de línguas, tanto o tratamento dos objetos de ensino e(m) gestos de transposição didática planificados, quanto as operações didático-discursivas (MATENCIO, 2001) necessárias à tematização e referenciação desses objetos na interação didática.

Daí as ponderações aqui realizadas se prestarem a demonstrar que professor e alunos têm suas identidades construídas também em função do modo como coatuam nas posições de falantes e ouvintes, haja vista certas restrições à palavra convencionais a um grupo. ${ }^{2}$

Para chegar à demonstração desse achado, o trabalho se organiza em mais cinco seções. A próxima será dedicada à apresentação teórico-metodológica proposta, espaço no qual indico a produtividade de princípios do dialogismo (VOLOCHÍNOV, 1999) e da abordagem (socio)interacionista derivada da abordagem de Mead (1962) e registro as condições de construção do corpus na coleta de dados na Alemanha e Brasil, a partir de uma perspectiva etnográfica de trabalho. Na seção 3 , Sala de aula como contexto institucional e interacional, mobilizo a associação das categorias psicofonatórias falante e ouvinte às sociais professor e alunos para analisar o intercâmbio da palavra na sala de aula. Em seguida, na seção, Palavra e(m) participação, recorro às noções de participação e agenciamento da palavra para

1 Pesquisa realizada com o auxílio das agências de fomento Capes e DAAD.

2 Com o uso do item lexical 'também', saliento que não desconsidero que os sujeitos agem orientados por representações sociais, tomadas como sistemas de crenças compartilhados, historicamente e ideologicamente determinados. (MOSCOVICI, 2004). 
demonstrar que a estrutura da interação didática pode contribuir para a compreensão das tarefas interacionais e institucionais de professor e alunos. Em Cenas de aulas, lido discursivamente com os dados a partir da mobilização das categorias de análise. O trabalho é encerrado com provocações acerca da relação palavra, sala de aula e formação do sujeito.

\section{A abordagem teórico-metodológica proposta}

O trabalho fundamenta-se em um quadro teórico em que se articulam os princípios do dialogismo (VOLOCHÍNOV, 1999) e do (socio)interacionismo (MEAD, 1962). A afiliação a Volochínov parametriza que se veja que a interação entre interlocutores funda, a um só tempo, a linguagem, a relação entre os sujeitos, os sentidos atribuídos na interação às palavras e os próprios sujeitos, considerando a faceta ideológica que reveste todo o comportamento humano, que a palavra acompanha e comenta, sendo réplica de um sentido ideológico e vivencial (VOLOCHÍNOV, 1999), ou seja, nem tudo está dado, nem tudo é criado no momento.

Daí dizer que (i) a linguagem e o sujeito estão inscritos em um processo sócio-histórico ideológico; (ii) a palavra (pensada ou exteriorizada na enunciação) é sempre réplica; (iii) o sujeito é dúplice e transitivo; (iv) interações sociais são atos humanos em que indivíduos (socialmente organizados) partem da ideologicidade consensual inscrita (e por eles ressignificada) na palavra para se relacionarem e, assim, se construírem sujeitos com o outro, para o outro e para si mesmos e, por fim, (v) os sujeitos assim se inter-relacionam, ou relacionam-se consigo mesmos (introspecção), com a ajuda de signos ideológicos dos quais se valem para se expressarem por palavras, mímicas, gestos, jogos de olhares ou por qualquer outro meio (VOLOCHÍNOV, 1999).

Já quanto ao (socio)interacionismo, este trabalho guarda a necessidade de não se pensar em interação sem considerar relações entre o espaço institucional e os sujeitos que lá desempenham suas funções. Com a consolidação do interacionismo, nessa vertente de Mead (1962) e de seu olhar para a instituição, abriu-se espaço para se pensar sobre o sujeito considerando suas identidades relacionais.

Daí enquadrar, aqui, a interação a partir de questões culturais pensando em Alemanha e Brasil como integrantes de uma cultura escolar ocidental e das particularidades reveladas no uso da palavra nas salas de aula, representantes de cada grupo, a partir da cultura escolar local. 
A perspectiva etnográfica, agenciada para acessar e participar da realidade escolar dos dois grupos, é que autoriza o enquadre da cultura escolar, o que faço adiante ao analisar as cenas de sala de aula dos grupos brasileiro e alemão. ${ }^{3}$

As pesquisas em campo de que os dados são provenientes foram realizadas a partir da observação de todas as atividades realizadas no horário escolar por dois grupos em uma mesma etapa de escolarização correspondente nos sistemas de ensino alemão e brasileiro: o hoje $5^{\circ}$ ano do ensino fundamental, antiga $4^{\mathrm{a}}$ série. O grupo alemão será aqui referenciado como vierte Klasse B (quarta série B) e o grupo brasileiro como sala $17 .^{4}$

Com a vierte Klasse $B$ convivi durante três meses, já a sala 17 foi acompanhada durante dois meses. Na maior parte desse tempo, os alunos ficaram sob a orientação de suas professoras regentes Frau Müller (Senhora Müller), grupo alemão, e Andréia Wolfgang, grupo brasileiro.

No meu estar em campo, assim como todos os movimentos posteriores de análise comparativa entre os dois grupos, orientei-me por três premissas etnográficas: i) o que se analisa poderia ser diferente; ii) o que se analisa (ou acreditamos estar analisando) é uma construção e iii) há razões que explicam o fato de os contextos observados não serem iguais (ERICKSON,1973, 2005; POWELL, 2006; SPINDLER, 2005; MCDERMOTT; VARENNE, 2005).

A comparação, portanto, que apresento neste trabalho, é aquela pela qual se interessa a etnografia, orienta-se pela descrição e análise do que há no grupo e não sobre o que falta, tampouco sobre o que, sob a ótica do pesquisador, deveria ser mudado (DIXON; GREEN; ZAHARLICK, 2005).

Desse modo, sumarizo que do dialogismo este trabalho guarda o fato de que a linguagem é a agulha que sutura todas as relações entre os sujeitos, o mundo e as coisas do mundo; do (socio)interacionismo advindo de Mead, salva-se o fato de que a convivência intersubjetiva na/da sala de aula é mais uma convivência institucional, sendo essa parte de "acontecimentos de manifestações particulares e formalizadas que fazem parte do processo de vida social da evolução humana"s (MEAD, 1962,

3 Vale lembrar que o termo etnografia recebe muitos encapsulamentos: concepção, método, metodologia, postura de trabalho, técnica de observação e parâmetros de ação são os mais recorrentes (BOUMARD, 1999; ERICKSON,1973, 2005; POWELL, 2006; SPINDLER, 2005; MCDERMOTT; VARENNE, 2005). Neste trabalho, a etnografia é tomada como uma lógica de investigação que oferece preciosos parâmetros para construções, descrições e explicitações do corpus.

4 Todos os nomes que integram este trabalho, usados para referenciar os grupos e os sujeitos, são fictícios, mas atualizam os modos de representar de cada realidade acompanhada.

5 Todas as traduções apresentadas neste trabalho são de minha responsabilidade, do original em inglês de Mead (1962), Holland et al. (1998), Gumperz e Gumperz (1982) e Merritt (1982). 
p. 262). Por fim, da etnografia advém o olhar para a sala de aula como mais um ambiente para se acessar o mistério da sociabilidade, por meio de um movimento pendular - em que se estuda sobre uma dada instituição, ora em termos mais amplos (como um fenômeno social constitutivo de toda e qualquer sociedade), ora como exemplar institucional de uma sociedade, de um grupo. Isso confere à etnografia o estatuto de viabilizar a abordagem de um fenômeno ou de um processo particular sem "que se exclua este processo da totalidade maior que o determina e com o qual mantém certas formas de relacionamento" (SATO; SOUZA, 2001, p. 31).

Antes da apresentação das cenas de sala de aula, é necessário capitalizar conceitos caros ao tratamento do objeto.

\section{Sala de aula como contexto institucional e interacional}

É na sala de aula que professor e alunos constroem coletivamente suas realidades diárias, o que fazem colocando em prática modelos de educabilidade (GUMPERZ; GUMPERZ, 1982) e exprimindo expectativas sociais diversas acerca da escola e daqueles que desse espaço participam. Assim, sejam quais forem as nossas perspectivas de análise - estudar a interação e a aprendizagem, a interação na aprendizagem e/ou a interação como contexto de aprendizagem (KLEIMAN, 1991) - a sala de aula será sempre, ao mesmo tempo, ponto de partida e chegada para pensarmos a formação do aluno como um sujeito de linguagem.

A sala de aula tradicional é um contexto de interação institucionalizado em que indivíduos reconhecidos como professor e alunos constroem suas identidades relacionais face a face, no dia a dia escolar, a partir de direitos e deveres interacionais.

Se cada sala de aula é uma microcultura (ERICKSON, 1990), ou seja, se ela traz marcas do que é local/circunstancial/característico e significativo para o grupo que ali convive, tudo que é dessa ordem é, em alguma medida, também atravessado por aspectos comuns de outras salas de aulas. Há, assim, sempre facetas institucionais de um funcionamento recorrente que nos permite dizer que estamos diante de uma sala de aula.

Princípios de um mesmo código cultural escolar (tudo aquilo que historicamente se cristalizou como característica da instituição escola) aparecem sob diferentes roupagens no cotidiano dos grupos, instituindo diferentes procedimentos para se cumprir certas restrições com vistas ao comportamento em sala de aula. 
A sala de aula como contexto institucional é

[...] um espaço já construído por um compartilhado 'complexo de convenções cuja visibilidade e continuidade são garantidas institucionalmente'. E os construtos linguísticos da comunicação institucional, ao mesmo tempo em que são marcados por necessidades práticas de padronização, indexicalizam sistemas de valores e objetivos assumidos como compartilhados pelo grupo de referência ou comunidade relevante. Nesse sentido, comunicar legitimidade é reafirmar uma presumida visão de mundo, própria de determinado grupo social (SIGNORINI, 2001, p. 150-151).

Neste trabalho, portanto, o que faço é indiciar visões de mundo próprias das turmas vierte Klasse $B$ e sala 17 revestidas por roupagens linguístico-discursivas nos/dos modos de se usar a palavra em sala de aula.

Se nascemos para nos comunicar e se é no curso de uma vida que aprendemos a ser sujeitos de linguagem, a sala de aula é um contexto dialógico ímpar na vida daqueles que lá participam, porque

[...] os indivíduos envolvidos no processo de vida social cujas instituições sociais são manifestações organizadas podem desenvolver e possuir eus ou personalidades completamente maduras à medida que cada indivíduo reflete, ou descobre a partir de sua experiência individual que estas atitudes e atividades sociais organizadas são incorporadas ou representadas pelas instituições sociais (MEAD, 1962, p. 262).

Professor e alunos se dirigem regularmente a um mesmo espaço físico (a sala de aula) para (co)desempenharem funções sociais estabilizadas e terem suas memórias dos laços socioafetivos (re)construídas, sobretudo, em função do tempo e da natureza dessa convivência intersubjetiva. A sala de aula é, por isso, porta de entrada para o domínio público das relações humanas e lugar genuíno de construção de pelo menos uma identidade social: a de aluno.

Assumo a necessidade de discorrer sobre padrões de comportamento (e o que eles informam em termos de traços culturais das relações interpessoais e interinstitucionais estabelecidas entre professor e alunos) considerando que, na aula, professor e alunos são também falantes e ouvintes.

Isso porque: i) as identidades discursivas institucionais de alunos e professor convergem com as posições de falante e ouvinte, que precisam ser assumidas de 
modo coordenado para que se tenha uma comunicação oral e, portanto, para que os sujeitos possam cumprir as tarefas interacionais de ensinar e aprender, que justificam o encontro social aula e ii) a troca didática em sala de aula é permeada por marcas (inter)culturais e por construções identitárias que determinam quem fala e como o faz; o que se faz ao falar; como se sinaliza que se quer falar e que se está ouvindo, além de como as falas e as tentativas para falar são significadas no grupo.

A imagem que um sujeito faz de si mesmo se molda e se remolda não apenas a partir do modo como esse sujeito compreende e significa suas ações, mas também em função das pistas dadas pelos outros sujeitos sobre o modo como suas ações estão sendo interpretadas. Esse jogo de (auto/alter)avaliações ocorre porque

[...] o ser humano, em suas interações, tende a agir de acordo com uma determinada linha de conduta, ou seja, um padrão de comportamento verbal e não verbal por meio do qual ele expressa sua visão das coisas e, por meio dessa, seu julgamento dos outros participantes e, especialmente, de si mesmo (BAPTISTA, 2002, p. 367).

Identidades são, assim, mediadas por comportamentos verbais e/ou não verbais que sofrem influências da cultura da escola e da cultura escolar do grupo. Assim, o "comportamento é mediado por sensos de self ou pelo que chamamos identidades" (HOLLAND et al., 1998, p. 5) e identidades são "os imaginários do self em mundos de ação, como produtos sociais", bem como "são recursos decisivos com os quais as pessoas se importam e cuidam do que está acontecendo ao redor delas" (HOLLAND et al., 1998, p. 5).

Ao intercambiar a palavra, os sujeitos aprendem a participar de contextos dialógicos diversificados, o que fazem (re)construindo identidades em uma rede de relações sociais e pessoais que se efetivam, preponderantemente, em torno da palavra.

No interior dos estudos linguísticos, falante e ouvinte se vinculam a categorias formais de análise, já que se prestam à descrição de um aspecto estrutural da interação oral: a alternância do turno de fala.

Falante e ouvinte são, nessa dimensão, funções psicofonatórias que precisam ser assumidas conjuntamente, simultaneamente e de modo intercambiado, por pelo menos dois sujeitos empíricos face a face ou a distância. Esse é o pré-requisito para a comunicação oral (SACKS; SCHEGLOFF; JEFFERSON, 1974). 
Como falante e ouvinte são posições demarcadas em função da palavra: quem age com a palavra é o falante e quem reage à palavra é o ouvinte, o problema de coordenação resulta obviamente da aceitação de papéis diferenciados a serem cumpridos pelos interlocutores, o que pressupõe que a colaboração dos interactantes é marcada no cumprimento de regras interacionais.

Matencio (2001) avança visivelmente na problematização da contribuição da noção de turno, já que traz a noção de intervenção contemplada no interior das unidades analíticas da aula. A autora defende que o recorte funcional da noção de intervenção, que se contrapõe ao recorte formal da noção de turno, precisa ser levado em consideração para se pensar em modelos estruturais e na análise hierárquica e funcional da aula, isso porque o uso da palavra "não é apenas um instrumento neutro, mas expressão direta da distribuição de poder" (EHLICH, 1994, p. 82).

Aqui, interessa-me a noção de turno como algo da ordem constitutiva do dialogal. Tomo, assim, o turno como a unidade formal da conversação e a alternância de turnos (na verdade, uma alternância de trocas entre falantes) como a unidade discursiva do texto falado que pode colocar em evidência a relação hierárquica entre os sujeitos e problemas de mal-entendidos pautados, por vezes, em questões de natureza político-cultural. Já a noção de intervenção revela o lugar e o valor atribuído ao turno de fala pelos sujeitos na aula (SACKS; SCHEGLOFF; JEFFERSON, 1974).

Numa abordagem interacionista e dialógica, como procurei sumariamente demonstrar aqui, não é possível pensar apenas em posições psicofonatórias (falante e ouvinte); por outro lado, só as categorias sociais (professor e alunos) não são suficientes para a natureza deste trabalho, tendo em vista que o tipo de indício que se ofereceu para cotejo das duas realidades passa pelo modo como os sujeitos se colocam como falantes e ouvintes nas cenas de interação.

\section{Palavra e $(\mathrm{m})$ participação}

Este trabalho, tal como informado na introdução, enfoca participação discente e palavra em duas salas de aula, geograficamente afastadas, para demonstrar que a sala de aula é mais um dos contextos dialógicos institucionais para se intercambiar a palavra e aprender a participar socialmente do mundo como sujeito de linguagem.

$\mathrm{O}$ que se faz (re)construindo identidades em uma rede de relações sociais e 
pessoais que se efetivam, preponderantemente, em torno da palavra e, portanto, como professor e alunos se comportam como falantes e ouvintes participando e, assim, constituindo a interação didática.

Há, assim, diferentes modos de se participar. Dizer e silenciar são ações de linguagem que marcam posições na interação com o outro e com o dizer do outro. Dentre as especificidades do que socialmente se reconhece como a prática de linguagem aula, tem-se fundamentalmente lançado o olhar para aquilo que acontece no solo da interação principal e, portanto, para aquilo que está sob gerência do professor, cabendo a este agenciar o funcionamento da palavra em sala de aula, do que faz parte incitar verbalizações e requerer silêncios.

$\mathrm{Na}$ aula, dado o número de sujeitos empíricos que ali participam, não é possível que todos falem ao mesmo tempo ou mesmo que todos falem em todos os momentos da aula. Nas vierte Klasse B e sala 17, temos grupos de 26 alunos (cf. mapas de sala, seção 5). Isso acaba convocando-nos a flexibilizar a ideia de participação em sala de aula como uso da palavra e, consequentemente, a rever o lugar que atribuímos à participação como ouvinte.

$\mathrm{O}$ que estou dizendo é que para o funcionamento da aula e, portanto, da interação didática, não poderíamos jamais reduzir a participação dos alunos à linguagem verbalizada e materializada em turnos de fala. Se assim o fizéssemos, alunos que não falam não existiriam discursivamente na aula e, portanto, não seriam considerados parte da turma.

O lugar de falante, quando assumido pelo aluno, figura uma participação verbalizada, quando pelo professor, para a gerência da palavra, exercício do poder enunciativo/discursivo a ele conferido institucionalmente na sala de aula. O que os sujeitos fazem, ou são capazes de fazer, em sala de aula, fazem, sobretudo, por meio da palavra falada ou com vistas a ela, o que, certamente, ocorre com o auxílio de outros sistemas semióticos.

A interação didática na sala de aula pode ser enquadrada, por meio de operações linguístico-discursivas basilares relativas ao uso ou tentativa de uso da palavra, tal como registra a tabela a seguir. 
QUADRO 1 - Operações linguístico-discursivas basilares da interação didática

\begin{tabular}{|c|c|c|c|}
\hline \multicolumn{4}{|c|}{$\begin{array}{l}\text { OPERAÇÕES LINGUÍSTICO-DISCURSIVAS } \\
\text { BASILARES DA INTERAÇÃO DIDÁTICA }\end{array}$} \\
\hline \multirow[b]{2}{*}{ NOME } & \multicolumn{2}{|c|}{ QUEM A REALIZA? } & \multirow[b]{2}{*}{ OBSERVAÇÕES } \\
\hline & $\begin{array}{l}\text { Posição } \\
\text { social }\end{array}$ & $\begin{array}{c}\text { Posição } \\
\text { psicofonatória }\end{array}$ & \\
\hline $\begin{array}{l}\text { Endereçamento } \\
\text { da palavra }\end{array}$ & $\begin{array}{l}\text { Professor e } \\
\text { aluno }\end{array}$ & Falante & $\begin{array}{l}\text { Fundamenta e principia toda } \\
\text { e qualquer interação. }\end{array}$ \\
\hline $\begin{array}{l}\text { Manutenção da } \\
\text { palavra }\end{array}$ & $\begin{array}{l}\text { Professor e } \\
\text { alunos* }\end{array}$ & Falante & $\begin{array}{l}\text { Há a expectativa na cultura } \\
\text { escolar de que a palavra seja } \\
\text { mantida quantitativamente } \\
\text { e qualitativamente com o } \\
\text { professor. }\end{array}$ \\
\hline $\begin{array}{l}\text { Tomada da } \\
\text { palavra }\end{array}$ & $\begin{array}{l}\text { Professor e } \\
\text { aluno* }\end{array}$ & Falante & $\begin{array}{l}\text { Um direito interacional do } \\
\text { professor. Pode haver, no } \\
\text { entanto, restrições culturais. } \\
\text { No grupo brasileiro, alguns } \\
\text { alunos tomam a palavra } \\
\text { espontaneamente. }\end{array}$ \\
\hline $\begin{array}{l}\text { Cassação da } \\
\text { palavra }\end{array}$ & Professor & Falante & $\begin{array}{l}\text { Um direito interacional do } \\
\text { professor que implica não } \\
\text { distribuir a palavra e não } \\
\text { permitir que ela seja tomada } \\
\text { pelos alunos. }\end{array}$ \\
\hline $\begin{array}{l}\text { Distribuição da } \\
\text { palavra }\end{array}$ & Professor & Falante & $\begin{array}{l}\text { Há a expectativa na cultura } \\
\text { escolar de que é o professor } \\
\text { o único falante autorizado a } \\
\text { distribuir a palavra. }\end{array}$ \\
\hline $\begin{array}{l}\text { Pedido da } \\
\text { palavra }\end{array}$ & Aluno & Ouvinte & $\begin{array}{l}\text { Indiciado, sobretudo, na } \\
\text { cultura escolar ocidental } \\
\text { com um levantar de mão ou } \\
\text { dedo indicador. Há outros } \\
\text { modos não verbais de } \\
\text { demonstrar desejo de falar } \\
\text { como meneios de cabeça, } \\
\text { abertura da boca ou emissão } \\
\text { de alguma vocalização. }\end{array}$ \\
\hline
\end{tabular}

FONTE: Elaborado pela autora. 
$\mathrm{O}$ quadro potencializa questões relativas à assimetria dos direitos de fala na aula. As relações de lugares (falante ou ouvinte) e papéis (professor e aluno) assumidos no decurso de socializações com vistas à interação didática levam em conta, como procurei sumarizar na tabela, uma realidade conversacional. Ora, nesses termos, a associação de categorias sociais (professor e alunos) a categorias formais e linguísticas (falantes e ouvinte) possibilita que se perceba que há muito mais na estrutura da interação do que a princípio se vê.

Embora a noção de palavra que a leitura da tabela requeira esteja mais vinculada à estrutura da interação, ou seja, ao uso da palavra (manutenção, tomada e distribuição) ou à sua tentativa (pedido e cassação), por meio da obtenção ou retenção do turno de fala, esse modo de usar a palavra ou de tentar obtê-la se articula sempre a um espectro de participação.

Ao observar os modos como os interactantes da vierte Klasse B e da sala 17 (não) respondem ao que é pelo outro enunciado, percebi que se pode falar em diferentes níveis de participação: as efetivadas, as laterais, as entreparticipações e as tentativas de participação, como sumariza a tabela abaixo. A diferença na natureza dessas participações resulta do agenciamento de operações linguísticodiscursivas, como também indicado no quadro. 
QUADRO 2 - Tipos de participação na interação didática em operações linguístico-discursivas

\begin{tabular}{|c|c|c|c|}
\hline \multicolumn{4}{|c|}{ TIPOS DE PARTICIPAÇÃO DISCENTE NA INTERAÇÃO DIDÁTICA } \\
\hline $\begin{array}{c}\text { Participação } \\
\text { efetivada }\end{array}$ & $\begin{array}{c}\text { Participação } \\
\text { lateral }\end{array}$ & Entreparticipação & $\begin{array}{l}\text { Tentativa de } \\
\text { participação }\end{array}$ \\
\hline $\begin{array}{l}\text { O aluno se } \\
\text { manifesta } \\
\text { explicitamente } \\
\text { para todo o grupo. } \\
\text { A participação } \\
\text { se dá no interior } \\
\text { do enquadre } \\
\text { interativo principal, } \\
\text { sendo ratificada } \\
\text { pelo professor, } \\
\text { que emite uma } \\
\text { avaliação. } \\
\text { A fala constitui } \\
\text { uma intervenção } \\
\text { (MATENCIO, } \\
\text { 2001) para o } \\
\text { texto oral em } \\
\text { coconstrução, } \\
\text { de que a aula é } \\
\text { resultado. }\end{array}$ & $\begin{array}{l}\text { O aluno fala, } \\
\text { dirigindo-se a todo } \\
\text { o grupo, e tem o seu } \\
\text { dizer considerado } \\
\text { por um ou vários } \\
\text { colegas. } \\
\text { Aqui não } \\
\text { estão incluídas } \\
\text { microinterações, } \\
\text { muito embora } \\
\text { essa forma de } \\
\text { participação possa } \\
\text { nelas resultar ou ser } \\
\text { delas resultado. } \\
\text { Razões pelas quais } \\
\text { o aluno geralmente } \\
\text { tem a sua fala } \\
\text { desconsiderada pelo } \\
\text { professor: este não } \\
\text { ouviu ou considera } \\
\text { inapropriado o } \\
\text { dizer, seja pelo que } \\
\text { foi dito, seja pelo } \\
\text { modo como o aluno } \\
\text { fez uso da palavra. }\end{array}$ & $\begin{array}{l}\text { O aluno chega a se } \\
\text { posicionar, mas o seu } \\
\text { dito é desconsiderado, } \\
\text { tanto pelo professor } \\
\text { quanto pelos colegas. }\end{array}$ & $\begin{array}{l}\text { O aluno mostra } \\
\text { um querer } \\
\text { participar, que } \\
\text { não se concretiza } \\
\text { porque o } \\
\text { professor não } \\
\text { autoriza que } \\
\text { este diga o que } \\
\text { pretendia dizer. } \\
\text { Alunos podem } \\
\text { concorrer à } \\
\text { participação; } \\
\text { vários se } \\
\text { inscrevem para } \\
\text { falar ao mesmo } \\
\text { tempo. }\end{array}$ \\
\hline \multicolumn{4}{|c|}{ Operações linguístico-discursivas } \\
\hline $\begin{array}{l}\text { Tomada, } \\
\text { manutenção e } \\
\text { endereçamento } \\
\text { da palavra na } \\
\text { interação principal. } \\
\text { Pode ou não ter } \\
\text { havido o pedido da } \\
\text { palavra. }\end{array}$ & $\begin{array}{l}\text { Sem o pedido } \\
\text { da palavra, o } \\
\text { endereçamento é } \\
\text { mal-sucedido e a } \\
\text { tomada da palavra } \\
\text { ocorre sem inserção } \\
\text { na interação } \\
\text { principal. Cassação } \\
\text { da palavra do aluno } \\
\text { pelo professor, já } \\
\text { que ele não autoriza } \\
\text { que esta seja } \\
\text { mantida pelo aluno. }\end{array}$ & $\begin{array}{l}\text { Embora a palavra } \\
\text { seja endereçada, ela é } \\
\text { ignorada, o que leva } \\
\text { automaticamente à sua } \\
\text { não manutenção, já que } \\
\text { não há engajamento de } \\
\text { ouvintes. Pode ter ou } \\
\text { não havido o pedido } \\
\text { da palavra. Em caso } \\
\text { positivo, o aluno não } \\
\text { aguarda a resposta } \\
\text { (distribuição da } \\
\text { palavra) do professor. }\end{array}$ & $\begin{array}{l}\text { Pedido da palavra } \\
\text { que pode não } \\
\text { se concretizar } \\
\text { por várias } \\
\text { razões, como a } \\
\text { palavra não lhe } \\
\text { foi distribuída } \\
\text { ou nem foi } \\
\text { distribuída (o } \\
\text { professor mantém } \\
\text { sua palavra, } \\
\text { cassando o direito } \\
\text { à palavra dos } \\
\text { alunos) ao grupo } \\
\text { de alunos. }\end{array}$ \\
\hline
\end{tabular}

FONTE: Elaborado pela autora. 
Mesmo ainda sem apresentar as cenas, registro, a fim de retomar adiante as exemplificações, os percentuais da natureza das participações rotineiras dos dois grupos, assegurado pelo quantitativo de dez aulas analisadas, que registram o recorrente observado em todo o período em campo.

\section{Sala 17}

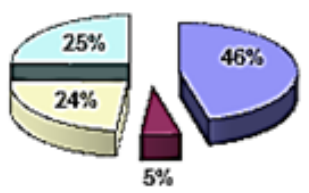

vierte Klasse $B$

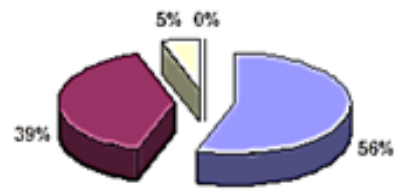

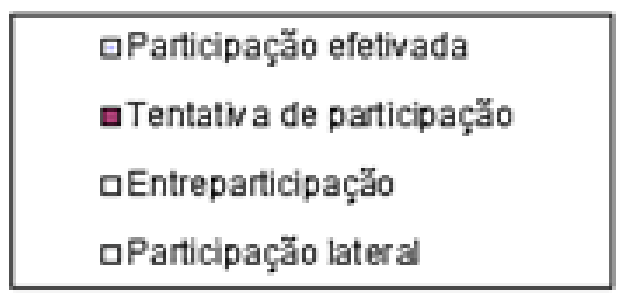

FONTE: Elaborado pela autora.

Podemos ler a similaridade no percentual das participações efetivadas nos dois grupos, $56 \%$ no alemão e $46 \%$ no brasileiro, como um direito interacional de contribuir para o tópico em construção no solo da interação principal da aula, o que é não apenas marca da cultura escolar ocidental, como também característica da prática de linguagem aula.

Já nas tentativas de participação, a pesquisa em campo atesta o que os dados apontam: os alunos alemães observados sinalizam que querem participar mais (39\%) do que os alunos do grupo brasileiro (5\%), o que se deve ao cumprimento da regra disciplinar 'inscrever-se para falar' que se materializa nos dois grupos mais recorrentemente no plano das ações não verbais, por meio do signo tradicional da cultura escolar ocidental levantar a mão.

A entreparticipação mostra que, quando alunos do grupo alemão tomam a palavra, fora de uma rotina do uso da palavra, o que ocorreu com incidência de $5 \%$, estes têm os seus dizeres desconsiderados, tanto pelo professor, quanto pelos colegas. Como os brasileiros se valem mais desse tipo de participação (24\%) é de 
esperar que o percentual seja não apenas bem diferente, mas que seja alto, afinal, se há mais falantes concorrendo à palavra no solo da interação principal, para que não haja problemas no tópico em referenciação nesse enquadre, é preciso que essas falas sejam, sim, desconsideradas.

Vemos que a participação lateral não ocorre no grupo alemão, sendo expressivo o percentual (25\%) no grupo brasileiro, o que se deve por duas razões principais, o pedido da palavra é uma operação linguístico-discursiva não tão seguida na cultura escolar brasileira, como o é na alemã, e poucos são os alunos alemães que se arriscam a tomar a palavra sem que ela tenha sido distribuída, como fazem muitos alunos do grupo brasileiro.

Acredito que refletir sobre a natureza das participações em sala de aula conduz a aspectos discursivos, como relações de poder, resistência a convenções institucionais e rotinas conversacionais apre(e)ndidas em outros espaços interacionais. Isso pode contribuir para se compreender melhor a complexidade da interação social em sala de aula, a diversidade da aprendizagem para o desenvolvimento dos sujeitos e o papel central do professor (WILKINSON, 1982).

Acessados os modos convencionais de participação de cada grupo, vejamos algumas especificidades contextuais que nos ajudarão na leitura adiante das cenas de sala de aula. As escolas, campos da pesquisa, integram a rede pública de ensino e estão localizadas em capitais de grandes estados da Alemanha e do Brasil. A etapa de escolarização dos grupos, como já informado, é correspondente, estando sob responsabilidade estadual no contexto alemão e municipal no contexto brasileiro. Segundo as leis alemã e brasileira, os alunos do ensino fundamental devem ser matriculados nas escolas mais próximas do endereço da residência. No caso do ensino fundamental, seja na Alemanha, seja no Brasil, é recorrente a figura de um professor regente, com formação em Pedagogia. Todos os alunos, 26 de cada grupo, estão em idade escolar compatível com a etapa de escolarização e não possuem histórico de reincidência em série escolar.

Passemos, agora, às cenas, que presentificam o recorrente e o episódico no dia a dia interacional dos dois grupos acompanhados.

\section{Cenas de aulas}

\section{Particularidades do grupo brasileiro}

Durante a pesquisa em campo, no contexto brasileiro, fui recorrentemente tomada pela sensação de que o ambiente da sala de aula 17 não era harmônico e, 
consequentemente, de que boa parte do grupo era dispersa ao que era tematizado pela professora; parecia faltar engajamento interacional. Nos momentos em que realizava as transcrições, no entanto, fui levada a reelaborar essa percepção.

A desarmonia do ambiente, interpretada em campo, fez com que eu, a ouvido nu, ouvisse inúmeras e repetidas sobreposições de vozes dos alunos. Os períodos de trabalho transcritivo e o cotejo das fitas de duas câmeras, posicionadas em diferentes pontos da sala, mostraram-me que frações de segundos separavam um turno de fala do outro e que os momentos em que dois sujeitos falavam ao mesmo tempo eram raros.

Levada a rever a hipótese de dispersão, cotejando as notas de campo ao trabalho de transcrição, percebi que três aspectos da rotina do grupo conduziram-me a essa interpretação, sendo eles:

a) a constatação de que alunos dirigiam a palavra a outros espacialmente distantes e falavam alto, o que explica, inclusive, a nitidez com que as câmeras capturaram o que se dizia;

b) um tipo de demanda da professora brasileira parecia sinalizar que não bastava que os alunos estivessem em silêncio, outros sinais de engajamento eram por ela requeridos;

c) o uso recorrente de certos vocativos pelas professoras brasileiras.

Como apontaram os percentuais das entreparticipações e participações laterais, na seção anterior, podemos ler nesses tipos de participação e nas microinterações sinais genuínos da provisoriedade da manutenção do foco de atenção do grupo brasileiro. Vejamos o mapa de sala do grupo e, em seguida, a primeira cena de aula.

$\begin{array}{lllll} & -\mathrm{P}- & & \\ \text {-Thaís- } & - \text { Vitor N- } & - \text { Felipe L- } & - \text { Lauanda- } & \text {-Ítalo- } \\ \text {-Vinícius- } & - \text { Felipe S- } & - \text { Nathã- } & - \text { Matheus- } & \text {-Ricardo- } \\ \text {-Rafael- } & - \text { Vítor H- } & - \text { Mylena- } & - \text { Márcia- } & \text {-Leandro- } \\ \text {-Mariana B- } & \text {-Ana- } & \text {-Lorrayne- } & - \text { Rebeca- } & - \text { Yan- } \\ \text {-Luís- } & - \text { Glauber- } & \text {-Mariana S- } & \text {-Izabela- } & \text {-Eduarda- } \\ \text {-Kelvin- } & & & - \text { Juciara- } & \text {-Raul- }\end{array}$

FIGURA 1 - Mapa de sala do grupo brasileiro Fonte: Elaborada pela autora. 
Cena $1^{6}$

31. P: psiu... pronto... Ricardo? senta direi:to ((Vinícius ainda está de pé)) Vinícius? ... psiu... sala dezessete por favor... Yan, Yan, você não FEZ [mas é pra você ficar] quieto aí TENTANDO corrigir... Luís Fernando cadê a folha assinada? ((o aluno se levanta e entrega a folha à $P$ ))... ô Ítalo tira essa folha do chão...tá bom ((diz a Luís Fernando depois de conferir a assinatura))... vamos lá "trabalhando com gráficos" Leandro? Leandro? eu estou corrigindo a atividade... de para-casa ((faz sinal indicando que o aluno abra o livro didático)).

Vemos aqui que P solicita silêncio ao grupo (31. P: psiu... pronto...) e, ao ser atendida, passando a ocupar sozinha a posição de falante, usa o enquadre interacional principal, não para a apresentação do que lhe cabe tematizar, mas para demandar mudanças de comportamentos não verbais de alguns alunos que a incomodam. Dois aspectos interessam-me aqui: (a) por que a professora faz isso? Ou seja, o que justifica sua ação, em termos de o que lhe parecem ser seus deveres profissionais?; e (b) estaria ela nesses momentos sinalizando que, mesmo em silêncio, esses alunos, a quem dirige a palavra, não estão se comportando como ouvintes 'ideais' e que não estariam se mostrando suficientemente engajados?

Essas perguntas se colocam porque, como a Cena 1 evidencia, o que $\mathrm{P}$, no turno 31, faz revela um padrão de comportamento. Prova disso é o aparecimento desse tipo de demanda em diferentes momentos de uma mesma aula, como endossa a numeração dos turnos de fala, a seguir:

\section{Exemplo 1}

51. P: quer dizer MUIto né? Rafael senta direito arruma sua cadeira Rafael... Rafael olha a cadeira põe a cadeira no meio da mesa olha aonde ela tá meu filho... cê tá quase caindo lá dentro... Vinícius? senta direito arruma a sua cadeira também... põe as pernas pra dentro... PLUVIÔ::METRO...presta atenção... Ricardo é pra corrigir tá? ((Ricardo apoia a cabeça com a mão)) 104. P: tira isso da orelha menino ((dirigindo-se a Ítalo))... Cabobró tem que escrever com letra MAIÚScula tá?

118. P: pronto Vitor Hugo? então tira o lápis da boca... "letra d discuta com seus colega e professor quais os possíveis prejuízos causados à vida da população pelo excesso de chuvas"

129. P: no Nordeste: é hora disso Leandro? ((Leandro está

6 Quanto às convenções de transcrição agenciadas, temos a demarcação de: (i) pausa (...); (ii) alongamento de vogal (::); (iii) entonação enfática, aumento de tom de voz (MAIÚSCULAS); (iv) leitura de textos durante a gravação (“ ”); (v) hipótese do que se ouviu [ ] e, por fim, (vi) comentários descritivos do transcritor $(())$. 
brincando com os materiais escolares e em silêncio mostra para $P$ que tem nas mãos uma tesoura e uma borracha)) Mais não é hora disso... tem uma cidade lá no Nordeste do Brasil que ela foi [TOTALMENTE DESTRUÍDA pela chuva]...

236. P: quatro... Leandro senta direitinho... na lateral aqui ela é partida né gente? ela é assim ó ((desenha no quadro)) né, então [na lateral] dela aqui ó a gente tem que contar direitinho, né?

P permite-se interromper o desenvolvimento do tópico/objeto de ensino (Cf. negritos nos turnos 51, 129,236) sob sua gerência ou adiar a tematização (como nos turnos 104 e 118) para realizar suas demandas. Desse modo, arrisco-me a dizer que não há dúvidas de que a natureza da demanda seja legítima para a professora, pois $\mathrm{P}$, ao fazer o que faz, não só altera momentaneamente o foco de sua atenção (a ponto de produzir digressões no texto falado em projeção no enquadre interativo principal), como também abre precedentes para que alunos, até então engajados como ouvintes, tenham sua atenção dispersada.

Interessam-me,portanto, aquimaisos efeitosdessesmomentosdeendereçamento da palavra individualizados, do que propriamente os endereçamentos, pois, como pondera Merritt (1982, p. 223), “[...] o tempo do professor é um bem escasso, há um professor para muitos alunos que podem ao mesmo tempo requerer a sua atenção". Pode-se perguntar, a essa altura, se as ações dos alunos advertidos relacionavam-se ou não a uma busca pela atenção da professora com o restante do grupo e em que medida o engajamento conversacional da professora com esses sujeitos foi produtivo para a interação principal.

Por meio do vocativo "gente", a professora brasileira se dirige aos alunos para monitorar a atenção do grupo, demonstrar que espera que o grupo responda ao que foi perguntado, frisar pedido de silêncio e incitar a participação. Por vezes, também, esses usos parecem se justificar por um desejo de dotar o que se está dizendo de uma certa interatividade, explicitamente marcada, como se verifica na Cena 2.

Cena 2

29. P: pra acabar com a discriminação... a gente ainda percebe que na NOSSA sociedade ainda existe né?... uma discriminação... com relação é::: aos negros, não é isso?... inclusive né gente? hoje em dia discriminar é ATÉ:: ... gente?

30. Rafael: crime

31. P: cri:me né? 
Aí o marcador discursivo "né" está associado ao vocativo em análise, o que parece potencializar a marcação de interatividade característica de algumas práticas orais, em que o foco de atenção parece precisar ser constantemente reafirmado.

Há algo cultural no uso do elemento linguístico "gente", que se explica até mesmo por sua função vocativa. $\mathrm{O}$ que estou dizendo é que, se no grupo brasileiro - diferentemente do alemão, como se verá adiante -, o professor precisa chamar constantemente o grupo, reivindicando atenção, está pressuposta a necessidade de regulação de algo que, na percepção do professor, falta ou se apresenta em baixa incidência. Nessa direção, o turno de fala 5, Cena 3, é relevante:

\section{Cena 3}

1. P: tem alguém que está com livro de hisTÓRIA?...

2. Raul: profe/ o dever...

3. P: alguém está com o livro de história?......... livro de HISTÓRIA aí por favor

4. Rafael: pode ser o livro de matemática?

5. P: quem está com o livro de história aí faz favor... ... ... OI... psiu...eu estou aqui ((repreendendo Vitor Nunes, Vinicius e Ítalo))... ... gente tem alguém que ESTÁ com o livro de história AÍ por favor.

Aqui a professora brasileira direciona uma pergunta para todo o grupo. Por meio do vocativo "gente", P procura evocar a atenção do grupo, já que apenas o aluno Rafael responde a ela, no turno 4, e ainda o faz de modo irônico. O que se pergunta no turno 5 pode ser interpretado como uma reformulação do que $\mathrm{P}$ diz nos turnos 1 e 3. Essa necessidade de reformulação (de modo a se ter que chamar, convocar, a atenção dos alunos para obtê-la) coloca $\mathrm{P}$ em uma posição interacional distinta da hierarquicamente instituída pela escola: a daquele para quem a atenção deve estar predominantemente voltada.

$\mathrm{Na}$ cena 4, a professora regente incita a participação do grupo, sem, como se pode perceber, selecionar quem ela gostaria que falasse e também sem perguntar quem gostaria de fazê-lo:

\section{Cena 4}

31. P: o que que é média anual?

32. Felipe Souza: é [é:::]

Lauanda: [é formal]

Eduarda: [é meio normal]

33. Natã: é uma média normal

34. P: não mé::dia:: ...ANUAL gente... 
É interessante notar que o vocativo em exame também foi recorrentemente acompanhado por "psiu", como prova o Exemplo 2 , em que são registrados três diferentes momentos de uma mesma aula:

\section{Exemplo 2}

74. P: psiu... GENTE vocês sabiam que aqui no Brasil é OBRI-GATÓRIO é:: o ensino da cultura é: é: africana

85. P: imprimir e colar aquele TÁ::NTO de fo:lha no cade:rno né? ((alguns alunos riem)) PSI::U... GENTE EU DISSE SEMPRE psi:: falei pra vocês que a pesquisa pode ser feita na interne:t

133. P: psi::u OLHA AQUI GENTE... PSIU A COLEGA DE VOCÊS AQUI Ó ELA DISSE QUE JÁ... VAMOS OUVI-LA? VAmos OUVI:: o que ela tem pra contar? ps:::

Nesses casos, P reforça o pedido de silêncio feito ao grupo, quando se valeu do vocativo "psiu", para marcar sua autoridade institucional de professora. O modo como os alunos lidam com essa imagem de autoridade influencia diretamente a provisoriedade da atenção que concedem ao dizer da professora.

Intervenções como essas, que integram os exemplos e cenas aqui apresentados, permitem afirmar que a professora brasileira tem que primeiro relembrar aos alunos que eles devem ouvi-las e para isso silenciar (criar condições para um foco de atenção comum), para só depois tentarem construir esse foco de atenção comum em termos temáticos, ou seja, do objeto de dizer que cabe a cada uma delas tematizar no interior da interação principal.

As análises dessas cenas e das do grupo alemão, na sequência, apontam para o fato de que temos bons motivos para crer que linguagem, cultura e sociedade realmente atravessam o modo como os interactantes atualizam seu trabalho institucional na escola. 


\section{Particularidades do grupo alemã $o^{7}$}

Com relação aos focos de atenção compartilhados, ficou evidenciado, como já discutido a partir do Gráfico 1, que os alunos raramente conversam entre si durante as aulas sem que isso seja pela professora demandado. Desse modo, em termos do que nos chama atenção Merritt (1982) acerca do envolvimento discente e concentração na/para a realização das tarefas, a professora alemã quase não precisa solicitar silêncio para o grupo. Microinterações são escassas e quando acontecem se dão no interior de um quadro interativo secundário tematicamente engajado ao primário e entre alunos vizinhos, que dividem uma mesma mesa. $\mathrm{O}$ gráfico da seção anterior sobre a natureza das participações respalda isso.

Daí se considerar que as condições mínimas para o estabelecimento do foco de atenção comum na interação principal já estão, a priori, postas. Ser ouvinte, ou seja, deixar que o professor (ou um outro aluno por ele autorizado) ocupe sozinho a posição de falante no enquadre interativo principal constitui um tipo de demonstração de engajamento central que está, portanto, pressuposto para o grupo alemão.

O fato de que não é preciso que Frau Müller (adiante L de Lehrerin, 'Professora') relembre ao grupo quais são as formas esperadas para que os alunos demonstrem engajamento deve-se a um histórico de convivência comum com algumas regras de socialização basilares da Grundschule (a escola do ensino fundamental) alemã. Há pelo menos três anos (desde a $1^{\mathrm{a}}$ Klasse), os alunos da vierte Klasse $B$ vêm aplicando um conjunto de regras conversacionais e disciplinares da, na e para a sala de aula. ${ }^{8}$

7 A escola alemã recebe um alto percentual de crianças filhas de pais estrangeiros e está situada em uma região relativamente central e comercial da cidade. $50 \%$ dos alunos da vierte Klasse B têm os dois pais estrangeiros e outros $25 \%$, apenas um. O alto índice de estrangeiros nesse bairro não é privilégio dessa cidade alemã, em que realizei o estágio de doutoramento. Trata-se de um fenômeno estatisticamente quantificado em todo o país desde os anos 90 , potencializado pelas crises migratórias atuais em toda a Europa. Frau Müller, professora regente do grupo alemão, é pedagoga, leciona alemão, matemática, HSU (Heimat- und Sachunterricht - Pátria e Ciência, disciplina com conteúdo programático afim à de História e Ciências na realidade brasileira), inglês, esporte, Kunst (Arte), Förderung Unterricht (Aula de reforço) e música para a vierte Klasse B, o que perfaz uma convivência de 23 horas-aula por semana com o grupo.

8 Os tipos de acordo existentes são dois: Unsere Gesprächsregeln (nossas regras de conversação) e o Klassenvertrag (contrato da sala). O Klassenvertrag aproxima-se aos "combinados" (respeitar o outro, não comer em sala de aula, etc.), firmados também entre professor e alunos na realidade escolar brasileira. Não há dúvidas de que regras como essas traduzem esforços da cultura escolar pela manutenção de um ambiente institucional compatível com o trabalho que se espera seja nele desempenhado. 
Considerando, assim, que a palavra é o motor do trabalho (interacional) de professor e alunos, centro a minha atenção nas quatro cláusulas que integram as "nossas regras de conversação" (unsere Gesprächsregeln) do grupo.

O referido contrato é sucinto e preciso ao prescrever duas condições para que os alunos assumam a posição de falante (1. Nós falamos alto e claro / Wir sprechen laut und deutlich; e 4. Nós nos inscrevemos para falar / Wir melden uns) ou de ouvinte (2. Nós ouvimos o outro com boa atenção / Wir hören anderen gut zu; e 3 . Nós não interrompemos / Wir rufen nicht dazwischen) na sala de aula.

Considerando que essas regras conversacionais existem, e que são seguidas com considerável rigor pela vierte Klasse $B$, opto por tomar o modo como elas são atualizadas no dia a dia escolar como a particularidade das relações interacionais do grupo a partir das quais os alunos alemães sinalizam atenção e engajamento, bem como a professora distribui sua atenção. Afinal, isso responde à indagação de Merritt (1982, p. 283): “[...] como um participante sinaliza que quer engajar-se, como isso é assegurado e como isso é anunciado?".

Dentre as quatro regras de conversação do grupo, Nós nos inscrevemos para falar talvez seja a mais valorizada pela professora, já que ela marca o terreno da didatização da palavra, sendo, também e talvez por isso, a mais acatada pelos alunos.

A inscrição para a fala efetiva-se na realidade alemã eminentemente no plano das ações não verbais, por meio do signo tradicional levantar a mão. Se alunos devem se inscrever para falar, ou seja, se devem demonstrar que querem participar oralmente, daí o pedido da palavra, é apenas no interior de um enquadre interacional principal que essa regra faz sentido. Em outras palavras, existem posições hierárquicas distintas em jogo que repercutem em como um aluno pode se tornar falante.

Como se espera que todo aluno que queira participar da interação sob gerência da professora, exteriorizando sua posição, solicite de modo não verbal a palavra (levantando a mão), vários alunos podem fazê-lo (quase) ao mesmo tempo. Daí dizer que, ao distribuir a palavra, a professora distribui também sua atenção. A busca de como a professora distribui a palavra, no contexto alemão observado, fornece pistas não só para a discussão das relações hierárquicas entre professor e alunos e a natureza linguística dessa interação, mas deixa entrever algo relativo ao modo como as crianças encenam o papel de aluno.

À guisa de ilustração, consideremos cenas de aulas que registram tanto o recorrente como o episódico. Como uma pista contextual, trago o mapa de sala onde 
estão registradas as posições dos alunos e o posicionamento de Frau Müller nos primeiros momentos da aula presentificados nos exemplos escolhidos.

$\begin{array}{lcc}\text { - Frau Müller - } & & \\ \text {-Julios - Anuca- } & \text {-Emily-Zara- } & \text {-Levin-Mathias- } \\ \text {-Luis - Alekssandra- } & \text {-Giulio-Simon- } & \text {-Dennis-Juliana- } \\ \text {-Nina - Hannah- } & \text {-Joseph-Armina- } & \text {-Funda-Patrick- } \\ \text {-Stephanie-Secde- } & \text {-Pirm-Paul- } & \text {-Marie-Elisa- }\end{array}$

FIGURA 2 - Mapa de sala da vierte Klasse B Fonte: Elaborada pela autora.

Nas Cenas 5 e 6, vê-se uma metodologia de correção de exercício coletiva que se mostrou recorrente durante a pesquisa de campo: um aluno lê em voz alta o enunciado da tarefa a ser corrigida, vindo, em seguida, sua resposta ao exercício, que é, imediatamente, controlada por um segundo aluno, a quem cabe emitir uma resposta como richtig (certo) ou informar, em termos sucintos, para toda a turma, o que está errado. Enquanto se descortina esse processo, os outros alunos, em silêncio, realizam as correções em seus cadernos e a professora observa tudo, intervindo apenas quando necessário.

Para que uma metodologia como essa funcione, é preciso não apenas que alunos se candidatem para a tarefa, mas que, dentre os alunos que se candidatem, a professora $(\mathrm{L})$ escolha alunos que tenham realizado as tarefas satisfatoriamente, caso contrário, a correção ficará inevitavelmente a cargo da professora, a qual assumirá uma das tarefas que deveriam ficar sob tutela de alunos. Para que se visualizem essas ponderações, tem-se as cenas:

\section{Cena 5}

((A professora até então assentada, apanha o livro de matemática, se levanta e caminha posicionando-se na frente da sala, Mathias, Keith, Emily pedem a palavra levantando a mão direita))

1.L: quem quer fazer o número quatro? Keith isso é um pedido para falar?...é?

wer mag die Nummer vier machen? Keith ist das eine Meldung?... ja?

((Mathias e Emily permanecem com a mão levantada)) 
2.Keith: é ja

((Mathias e Emily permanecem com a mão levantada))

3.L: leia em voz alta e:: .. Mathias controla lies vor $u::$ nd .. Mathias kontrolliert

4.Keith: "a mala de mão de Lisa pesa quatro vírgula cinco quilos... a mala DEla está vinte e cinco quilos e quatrocentos gramas pesada "Lisa's Handgepäck wiegt vier Komma fünf Kilogramm... Ihr Koffer ist fünfundzwanzig Kilogramm und vierhundert Gramm schwer

((Os alunos dizem de modo sussurrado)): [mais pesado] ((corrigindo a colega))

[schwerer]

mais pesado mais pesado mais pesado ((repete a aluna de modo rápido)) é::

schwerer schwerer schwerer é::

"parte do conteúdo da bagagem de mão ela tem que colocar na mala no serviço de entrega de bagagem... agora a bagagem de mão pesa só dois quilos e novecentos gramas... pergunta... quanto ela tem que ainda pagar? cálculo... quatro vírgula cinco quilos dois vírgula novecentos quilos é um mil e seiscentos"

"einen Teil des Handgepäcks muss sie bei der Gepäckaufgabe in den Koffer packen... nun wiegt das Handgepäck nur noch zwei Kilogramm und neunhundert Gramm ... Frage... wie viel muss Lisa noch bezahlen?" Rechnung... vier Komma fünf Kilogramm zwei Komma neunhundert Kilogramm ist eintausendsechshundert”,

5. Mathias: e sete quilos vezes sete e:uros und sieben Kilogramm mal sieben eu:ro

6. Keith: é é verdade é...e...é:: a Lisa precisa pagar ainda quarenta e nove euros

ja ja stimmt ja...und ...é:: die Lisa muss noch neunundvierzig Euro bezahlen

7. Mathias: certo richtig

8. L: ótimo... isso foi de fato muito bom

Prima... die war nämlich ganz gut

9. Pirm ((falando baixo e sem se inscrever)): isso foi difícil das war schwierig 
((Mathias e Simon pedem a palavra levantando a mão))

10. L: - DI-FÍ-cil? quem conseguiu quem então reSOlveu? ((Quase todos os alunos levantam a mão)) ah:::.:: ó:::timo...ta:ntas crianças conseguiram resolver uma tarefa tão difícil... então vocês poderiam ficar orgulhosos de si mesmos... a PRÓXIMA será de novo um pouquinho mais fácil... não é?... quem quer fazê-la? Simon lê... Mathias controla

SCH-WIE-rig? wer hat denn die geschAfft wer hat denn die geLÖst? a::.: su:.:per...so vi:ele Kinder haben eine so schwere Aufgabe gelöst... da könnt ihr stolz auf euch sein... dIE NÄCHSTE wird wieder ein bisschen leichter gell?... wer mag die machen? Simon liest vor... Mathias kontrolliert

Quando, no primeiro turno de fala, a professora inicia a aula incitando a participação, três alunos já haviam demonstrado o desejo de falar. Isso provavelmente explica a necessidade de L se certificar se o gesto de inscrição remete a um pedido da palavra ou a um pedido da palavra para leitura do exercício.

Ainda no turno 1, L dirige a palavra a Keith, cuja resposta (em 2) parece ser generalizada por $\mathrm{L}$ aos outros dois alunos que ainda pedem a palavra. Essa generalização da professora poderia ser interpretada como: (i) uma pressuposição de que Mathias e Emily não permaneceriam com a mão levantada se quisessem por outro motivo falar, já que ela sugere, em seu primeiro turno de fala, o tipo de participação que a ela interessava; ou (ii) a professora se esquiva de qualquer possível alteração do desenvolvimento temático da aula por ela traçado, ${ }^{9}$ mesmo antes do início oficial da aula em curso.

Como se vê, na Cena 5, a professora escolhe prontamente a aluna Keith para ler, mas o alongamento de vogal que realiza (em 3) deixa entrever o fato de que ela avalia, olhando para os alunos, que estão com a mão levantada, quem será o segundo aluno a ser escolhido, optando por Mathias.

Keith dá início ao seu trabalho, em 4, e já nos primeiros momentos de leitura divide a posição de falante, o que ocorre em frações de segundo por uma sobreposição de sua voz à de alguns colegas que a corrigem. Esse aspecto, o primeiro dos raros a que me referi, merece ser aqui contextualizado. Como registra o mapa de sala, os alunos que corrigem Keith estão sentados próximo a ela e o fazem de modo muito baixo. Fica, portanto, registrado que essa ocorrência,

9 A professora, por exemplo, dirige a palavra a esses dois alunos, mas não procura se informar sobre o que eles gostariam de tematizar ou se queriam falar sobre alguma dúvida específica. 
embora singular no corpus, não poderia ser desconsiderada, tendo em vista o desconforto (e eu me arrisco a registrar o susto da aluna por ter sido pelos colegas contestada) que Keith deixa transparecer no modo como dá continuidade à leitura do enunciado do problema matemático no turno de fala 6 .

O modo como Mathias cumpre sua parte no par interacional com Keith, no turno 7, deixa à mostra a atenção com que ouvia a colega e a seriedade com que cumpre sua tarefa, o que Keith não só aceita, como a conduz à formulação no turno 8. A experiência de Mathias em sessões de correção como essas, ao contrário da colega, fica deflagrada em seu turno de fala 7, porque o que ele faz é apontar para a colega que ela se esqueceu de uma parte necessária: descrever a operação matemática básica por ela utilizada.

Já no turno 10, L não deixa explicitamente marcado qual é o referente de seu elogio, se a troca estabelecida anteriormente entre os dois alunos ou até mesmo o modo como o grupo como um todo se comportou durante a correção da tarefa. Mas o que é, a meu ver, mais importante aqui é o efeito de sentido provocado pela sua avaliação: a sugestão de que o trabalho interacional de Keith e Mathias terminava naquele momento.

A fala de Pirm, em 11, materializa o segundo aspecto pouco recorrente: a fala sem inscrição. Quando se fala nessas condições, L tende a desconsiderar a fala do aluno e os outros alunos nunca respondem verbalmente na forma de comentário ou alguma expressão avaliativa o que foi dito pelo colega, assim como acontece aqui. Entretanto, como se vê no turno 10, L opta por considerar a fala do aluno repetindo-a de modo a incitar a participação de todo o grupo.

Há alunos que, como a aluna Funda, a seguir na Cena 6, se inscrevem, aguardam pela atenção da professora e, ao ver que não terão o direito à palavra, demonstram verbalmente, como no turno 19, com o uso do vocativo "Frau Müller", que desejam engajamento na interação principal. Interessante, aqui, é notar que Funda não chega a tomar a palavra no turno 19, porque apenas reafirma verbalmente a sinalização não verbal, ou seja, a aluna só realmente se posiciona quando a professora autoriza que ela o faça, o que ocorre no turno 20.

\section{Cena 6}

13. Simon: É... "o voo... o trajeto do voo Frankfurt-Bremen é arredondando de trezentos quilômetros... De Frankfurt a Moscou é seis vezes mais distante... pergunta a... qual é a distância de Frankfurt a Moscou?"

Ähm... "die Flug... die Flugstrecke Frankfurt-Bremen ist rund 
dreihundert Kilometer lang... Von Frankfurt nach Moskau ist es sechsmal so weit... Frage a... Wie weit ist es von Frankfurt nach Moskau?"

14. Mathias: certo

richtig

15. Simon: A:h seis vezes trezentos é mil e oitocentos A:ch sechsmal dreihundert ist eintausendachthundert

16. Mathias: seis...VEzes trezentos quiLÔmetros é mil e oitocentos quilômetros

Sechs... MAl dreihundert KILOmeter ist tausendachthundert KILOmeter

((Funda levanta a mão e aguarda))

17. Simon: de Frankfurt a Moskou são mil e oitocentos quilômetros von Frankfurt nach Moskau sind es tausendachthundert Kilometer

18.Mathias: certo

richtig

((Funda está com a mão levantada e olha aflita para L., que não olha em sua direção))

19. Funda ((diz em tom baixo de voz e ainda mantendo a mão levantada)) senhora Müller?

Frau Müller?

20. L: Funda

21.Funda ((lendo sua resposta)): “demora de Frankfurt a Moscou mil e oitocentos quilômetros"

es dauert von Frankfurt nach Moskau tausendachthundert Kilometer

22. L: $\operatorname{sim} .$. mas DEMORA é um tempo e a pergunta é "qual é a distância?"... sim?

ja... aber es DAUERT ist eine Zeit und es heißt aber ,wie weit ist es" "..ja?

((10 segundos de pausa))

23. Funda: senhora Müller?

Frau Müller

((Giulio está com a mão levantada)) 
24.L: TAMbém uma pergunta? ((Giulio abaixa a mão)) AUch eine Frage?

((L parece se dirigir aqui a Giulio, já que seu olhar se volta para a direção desse aluno, ele, contudo, não se reconhece como interlocutor a quem a palavra foi endereçada, o que parece não incomodar Frau Müller, já que a professora não repete a pergunta)).

Funda talvez só tenha conseguido apresentar sua dúvida para L, em 21, porque agiu estrategicamente: não chegou a infringir totalmente a regra, porque manteve a mão levantada até que lhe fosse concedida a palavra, minimizando os efeitos negativos de a aluna ter chamado a professora, o que não dá certo no turno 23 .

L não considera, no turno 22 , que talvez sua resposta possa não ter sido suficientemente esclarecedora para Funda e, mesmo ouvindo a aluna, desconsidera seu pedido da palavra, talvez porque tenha se dado de modo inapropriado.

Como se pode ver, mesmo que sumariamente a partir dos exemplos anteriores, a palavra não é, na maior parte das vezes, tomada, mas sim concedida, na realidade alemã observada. E sendo concedida, pode-se levantar a hipótese de que essa concessão não é realizada prontamente por aquele que detém o direito sobre a palavra (o professor).

Registro que a espera pelo direito à fala por parte do aluno pode provocar certas "falhas"10 quando da tomada da palavra, já que, por vezes, o aluno pode esperar tanto que, quando chega o momento de se pronunciar, o que planejava dizer (sua intervenção) pode não ser mais adequado, tendo em vista o que foi por último tematizado.

Há ainda que se considerar que a insistência manifestada por alguns alunos poderia sinalizar um desejo de tentar responder a uma pergunta da professora, independentemente de seu teor. Ou seja, os alunos poderiam, por outro lado, apenas querer participar.

Se para falar (sendo socialmente aceito na cultura da sala de aula alemã) a inscrição é preliminarmente requerida, isso acaba sendo um conhecimento do grupo sobre o qual se pode operar até mesmo de modo estratégico, demonstrando para o professor que se é (ou se quer ser) participativo. Isso se pensarmos que a inscrição remeta a uma concorrência na participação (na Cena 5, cinco alunos solicitam a palavra, tendo esta sido a três deles concedida).

10 "Falhas", já com aspas, no sentido em que Kerbrat-Orecchioni (1996) as toma: gagueios, balbucios e lapsos, frases inacabadas ou tortuosas, repetições e retificações. 
Há alunos que já se inscrevem antes mesmo de saber o que será perguntado e há outros que desistem de suas formulações e permanecem com a mão levantada porque (como bons alunos que são) muito provavelmente saberão qualquer resposta. Essa hipótese faz eco à concepção de Erickson (2004, p. 54) de que em uma aula "[...] crianças disputam por atenção e engajamento conversacional com um único adulto.”.

Um questionamento, nessa altura, parece-me profícuo: o direito à palavra e, assim, a intervir não é de algum modo apagado ou negligenciado quando o aluno não pode formular o que pretendia dizer? Nessa medida, a inscrição para a fala parece ser pela professora tomada apenas como uma predisposição para participar e não como um momento de externalização de dúvidas e/ou perspectivas. Isso se deve pesar em uma discussão sobre o direito à fala em sala de aula.

A possibilidade de, na realidade brasileira, o aluno, por meio de uma sobreposição de vozes, atacar o turno, conseguindo, se não já materializar o que pretendia dizer, pelo menos provocar uma momentânea interrupção (que leve, por exemplo, a um ajuste no foco discursivo), na fala do professor, poderia ser nessa direção tematizada.

\section{Considerações finais}

Considerando que "a principal razão para participar é a necessidade de comunicação interpessoal” (BAPTISTA, 2002, p. 366) e que “[...] o uso da linguagem é governado por normas culturais, subculturais e de contextos específicos" (GUMPERZ; GUMPERZ, 1982, p. 13), as cenas de aulas conduzem a afastamentos e aproximações comportamentais que se materializam no entorno da palavra, isto é, analisando o funcionamento da palavra e o uso que os sujeitos fazem dela, acessamos padrões de comportamentos intragrupais e intergrupais que traçam (e, ao mesmo tempo, carregam traços) da cultura da escola e da cultura escolar local.

Em termos das operações discursivas no entorno da palavra, pudemos perceber que a professora alemã tem mais controle da palavra do que a docente brasileira. A 'distribuição da palavra' lhe é, pode-se dizer, exclusiva, sendo que cabe a ela decidir-se pela 'concessão ou cassação da palavra' aos alunos que a solicitam. Quando a 'tomada da palavra' ocorre - por não ser direito interacional do aluno, já que a realidade escolar alemã impõe aos alunos o seu pedido -, ela reverbera, na 
maior parte das vezes, em 'tentativas de tomada de palavra', visto que os outros participantes tendem a desconsiderar o que se disse naquele momento em que se fez uso da palavra. O descumprimento da regra, desse modo, faz com que os outros interactantes não se coloquem, projetem no par interlocutivo, reconhecendo-se como sujeitos a quem se 'endereçou a palavra', ou seja, eles não assumem suas posições como interlocutores em momentos como esses. A professora, ao poder 'manter a palavra', sem falantes concorrentes desautorizados e, portanto, sem microinterações desvinculadas da interação principal, sob sua gerência, faz desta um bem inalienável nesse espaço discursivo e interacional.

Já no que diz respeito à realidade conversacional da sala 17 , vimos que nem sempre é necessário que a professora 'distribua a palavra', porque, embora seja recomendável e esperado que os alunos sinalizem ao professor a necessidade de participar fazendo uso da palavra, muitas vezes, a sinalização já é, em si, uma 'tomada da palavra', o que requer um saber operar sobre os modos socialmente aceitos e instituídos de se comportar em sala de aula (como não interromper o professor, fazê-lo em momentos de pausas e no interior do foco de atenção principal). Caso contrário, o que o aluno faz quando 'toma a palavra' tende a ser desconsiderado pelo professor, mas pode ser, como vimos em exemplos, considerado por outros alunos, desencadeando, muitas vezes, microinterações entre pares. A presença de falantes concorrentes à posição ocupada pela professora brasileira na interação principal repercute em sua dificuldade de 'manutenção da palavra', o que leva, na maior parte das vezes, a uma 'concorrência à palavra', conduzindo o professor a 'endereçar a palavra' para determinados integrantes do grupo, operar reprimendas e solicitar, de modo reiterado para si como falante, o foco de atenção dos alunos.

Observar o agenciamento da palavra conduz à percepção da proximidade social entre participantes, suas relações hierárquicas, direitos e deveres institucionais, possibilitando que se entrevejam as chaves com que professor e alunos não apenas interagem, mas também se socializam, e as ferramentas com as quais operam a ideia de disciplinarização que alicerça as interações.

Sinalizo, assim, que as cenas analisadas ilustram a importância de se fazer do agenciamento da palavra uma categoria de análise para se refletir sobre o que o professor faz, ou pode fazer

[...] através da linguagem em sua prática em sala de aula, e utilizar esse conhecimento (pensando-se em expedientes de formação 
do professor) como um instrumento de trabalho a mais para se compreender a própria organização da interação em sala de aula (MATENCIO, 2001, p. 42).

Espero, assim, ter delimitado a importância de se ter levado em conta que, na aula, professor e alunos são também falantes e ouvintes. Isso possibilita que se discorra sobre padrões de comportamento (e o que eles informam em termos de traços culturais das relações interpessoais e interinstitucionais estabelecidas entre professor e alunos) dos dois grupos, levando em consideração tanto a estrutura como a função da palavra. Nesses termos, aproximamo-nos de um olhar que seja capaz de integrar as dimensões didática e discursiva da interação para compreender como a sala de aula pode ser mais um contexto dialógico para a formação do sujeito.

\begin{abstract}
The goal of this paper is to discuss about the didactic interaction as one of the true dialogic and discursive contexts for the formation of the subject taking into consideration the use of the word in society. Assuming an interactional (Mead, 1962) - dialogic view (Volochínov, 1999) and methodologically anchored in ethnographic principles, scenes from the didactic interaction of two groups (one German and other Brazilian), of the same level of schooling are brought, to demonstrate that the use of the word in the classroom. In other words, the way that teacher and students stand as speakers and listeners in their day-to-day interactions is submitted to cultural conventions, both in terms of an occidental school culture, and of a local school culture.
\end{abstract}

Keywords: Didactic interaction. Classroom. Formation of the subject. School culture. Word in the classroom.

\title{
Referências
}

BAPTISTA, Patrícia Rodrigues Tanuri. Capítulo 20 - O eu e o outro em interações ouvinte-locutor de rádio: um estudo da co-construção das identidades sociais. In: LOPES, Luiz Paulo da Moita; BASTOS, Liliana Cabral (Org.). Identidades: recortes multi e interdisciplinares. Campinas, SP: Mercado de Letras, 2002. p. 365-388.

COELHO, Fernanda de Castro Batista. Construção identitária e(m) comportamentos na sala de aula: o agenciamento da palavra em dois grupos (um 
alemão e um brasileiro). Tese (Doutorado em Linguística) - Pontifícia Universidade Católica de Minas Gerais, Belo Horizonte, 2011.

DIXON, Carol N.; GREEN, Judith L.; ZAHARLICK, Amy. A Etnografia como uma lógica de investigação. Educação em Revista, Belo Horizonte, n. 42, p. 13-79, dez. 2005.

EHLICH, Konrad. Análise da Atividade Verbal. Tradução de Carmem Zink Bolognini. Trabalhos em Linguística Aplicada, Campinas, SP, n. 21, p. 79-93, jan./jun. 1994.

ERICKSON, Frederick. What makes school ethnography "ethnographic"? Council on Anthropology and Education Newsletter/Antropology \& Education Quarterly, Boston, v. 4, n. 2, p. 10-19, 1973.

ERICKSON, Frederick. Qualitative methods in research on teaching In: WITTROCK, Merlin C. (Org.). Handbook of research on teaching. $3^{\text {rd }}$ ed. New York: Macmillan Publishing Company, 1990. p. 119-158.

ERICKSON, Frederick. Studying side by side: collaborative action ethnography in educational research. In: SPINDLER, George; HAMMOND, Lorie (Org.). Innovations in Educational Ethnography: theory, methods and results. New Jersey: Lawrence Erlbaum Associates, 2005. p. 235-258.

GUMPERZ, Jenny; GUMPERZ, John. J. Communicative Competence in Educational Perspective. In: WILKINSON, Louise Cherry (Org.). Communicating in the classroom. New York: Academic Press, 1982. p. 13-26.

HOLLAND, Dorothy; LACHICOTTE, William Jr.; SKINNER, Debra; CAIN, Carole. Identity and Agency in Cultural Worlds. London: Harvard University Press, 1998. KERBRAT-ORECCHIONI, Catherine. Análise da conversação: princípios e métodos. São Paulo: Parábola, 1996.

KLEIMAN, Angela B. Introdução. E um início: a pesquisa sobre interação e aprendizagem. In: Trabalhos em Linguística Aplicada, Campinas, SP, v. 18, p. 5-14, jul./dez. 1991.

MATENCIO, Maria de Lourdes Meirelles. Estudo da língua falada e aula de língua materna: uma abordagem processual da interação professor/alunos. Campinas, SP: Mercado de Letras, 2001.

MCDERMOTT, Ray; VARENNE, Hervé. Reconstructing culture in educational research. In: SPINDLER, George; HAMMOND, Lorie (Org.). Innovations in Educational Ethnography: theory, methods and results. New Jersey: Lawrence Erlbaum Associates, 2005. p. 3-32. 
MEAD, George H. Mind, self and society. Chicago: University of Chicago Press, 1962. Original publicado em 1934.

MERRITT, Marilyn. Distributing and directing attention in primary classrooms. In: WILKINSON, Louise Cherry (Org.). Communicating in the classroom. New York: Academic Press, 1982. p. 223-244.

MODL, Fernanda de Castro; RIBEIRO, Pollyanne Bicalho. Realinhamento Identitário do (futuro) professor: efeitos representacionais no e pelo relatório de estágio. Eutomia, Recife, v. 15, n. 1, p. 267-287, jul. $2015 \mathrm{a}$.

MODL, Fernanda de Castro; RIBEIRO, Pollyanne Bicalho. (Re)Construção Identitária em movimentos de referenciação: representações sociais sobre o professor na formação inicial. Nonada, Porto Alegre, n. 24, p. 61-82, 1. sem. 2015 b.

MOSCOVICI, Serge. Representações Sociais: investigações em psicologia social. Tradução de Pedrinho A. Guareschi. Petrópolis: Vozes, 2004.

POWELL, Kimberly. Inside-Out and Outside-In: participant observation in Taiko Drumming. In: SPINDLER, George; HAMMOND, Lorie (Org.). Innovations in Educational Ethnography: theory, methods and results. New Jersey: Lawrence Erlbaum Associates, 2006. p. 33-64.

SACKS, Harvey; SCHEGLOFF, Emanuel A.; JEFFERSON, Gail. A Simplest Systematics for the Organization of Turn-Taking for Conversation. Language, v. 50, n. 4, p. 696-735, Dec. 1974.

SATO, Leny; SOUZA, Marilene. Contribuindo para desvelar a complexidade do cotidiano através da pesquisa etnográfica em psicologia. Psicol. USP, São Paulo, v. 12, n. 2, p. 29-47, 2001.

SIGNORINI, Inês. Figuras e modelos contemporâneos da subjetividade. In: SIGNORINI, Inês (Org.). Língua(gem) e identidade: elementos para uma discussão no campo aplicado. Campinas, SP: Mercado de Letras, 2001. p. 333-380.

SOBRAL, Adail. Que pesquisa? Qual ensino? Linguagem \& Ensino, Pelotas, v. 16, n. 1, p.237-260, jan./jun. 2013.

SPINDLER, George. Living and writing ethnography: an exploration in selfadaptation and its consequences. In: SPINDLER, George; HAMMOND, Lorie (Org.). Innovations in Educational Ethnography: theory, methods and results. New Jersey: Lawrence Erlbaum Associates, 2005. p. 65-81.

VOLOCHÍNOV, Valentin Nikolaevich. Marxismo e Filosofia da Linguagem. Tradução de Michel Laud e Yara Frateschi Vieira. 8. ed. São Paulo: Hucitec, 1999. 
Original publicado em 1929.

WILKINSON, Louise Cherry. Introduction: a sociolinguistic approach to communicating in the classroom. In: WILKINSON, Louise Cherry (Org.). Communicating in the classroom. New York: Academic Press, 1982. p. 3-12.

ZANDWAIS, Ana. Demandas da pesquisa e diálogos entre teoria e prática. In: LEFFA, Vilson; ERNST, Aracy (Org.). Linguagens: metodologias de ensino e pesquisa. Pelotas: Educat, 2012. p.13-26.

Submetido em: 17 de junho de 2015. Aceito para publicação em: 09 de outubro de 2015. 
